\title{
Reduced mRNA abundance of the main enzymes involved in methionine metabolism in human liver cirrhosis and hepatocellular carcinoma
}

\author{
Matías A. Avila ${ }^{1 *}$, Carmen Berasain ${ }^{1 *}$, Luis Torres ${ }^{2}$, Antonio Martín-Duce ${ }^{3}$, Fernando J. Corrales ${ }^{1}$, \\ Heping Yang ${ }^{4}$, Jesús Prieto ${ }^{1}$, Shelly C. Lu ${ }^{4}$, Juan Caballería ${ }^{5}$, Juan Rodés ${ }^{5}$ and José M. Mato ${ }^{1}$ \\ ${ }^{1}$ División de Hepatología y Terapia Génica, Departamento de Medicina Interna, Universidad de Navarra, ${ }^{2}$ Departamento de Bioquimica y Biología \\ Molecular, Universitat de València, Burjassot and ${ }^{3}$ Servicio de Cirugia, Hospital Principe de Asturias, Alcala de Henares, Spain; ${ }^{4}$ Center for \\ Disease Liver Research and Division of Gastrointestinal Liver Diseases, Department of Medicine, University of Southern California School of \\ Medicine, Los Angeles, CA, USA; and ${ }^{5}$ Servicio de Hepatologia, Institut de Malalties Digestives, Hospital Clinic, IDIBAPS, Universidad de \\ Barcelona, Barcelona, Spain
}

Background/Aims: It has been known for at least $\mathbf{5 0}$ years that alterations in methionine metabolism occur in human liver cirrhosis. However, the molecular basis of this alteration is not completely understood. In order to gain more insight into the mechanisms behind this condition, mRNA levels of methionine adenosyltransferase $(M A T 1 A)$, glycine methyltransferase (GNMT), methionine synthase (MS), betaine homocysteine methyltransferase (BHMT) and cystathionine $\beta$-synthase $(C B S)$ were examined in 26 cirrhotic livers, five hepatocellular carcinoma (HCC) tissues and ten control livers.

Methods: The expression of the above-mentioned genes was determined by quantitative RT-PCR analysis. Methylation of $M A T 1 A$ promoter was assessed by methylation-sensitive restriction enzyme digestion of genomic DNA.

Results: When compared to normal livers MAT1A,

$\mathrm{T}$ HE LIVER has the dual task of converting methionine, via S-adenosylmethionine (AdoMet) and Sadenosylhomocysteine (AdoHcy), into homocysteine, followed by reconversion of homocysteine into methionine while feeding the transsulfuration pathway that leads to the formation from homocysteine of cysteine and glutathione (GSH) (Fig. 1). The two pathways are

* Both authors made equal contribution to this work.

Received 18 April; revised 19 June; accepted 26 June 2000

Correspondence: José M. Mato, Edificio Los Castaños, División de Hepatología y Terapia Génica, Departamento de Medicina Interna, Universidad de Navarra, 31008 Pamplona, Spain. Tel: 34948425678.

Fax: 34948 425677. e-mail: jmmato@unav.es
GNMT, BHMT, $C B S$ and $M S$ mRNA contents were significantly reduced in liver cirrhosis. Interestingly, $M A T 1 A$ promoter was hypermethylated in the cirrhotic liver. HCC tissues also showed decreased mRNA levels of these enzymes.

Conclusions: These findings establish that the abundance of the mRNA of the main genes involved in methionine metabolism is markedly reduced in human cirrhosis and HCC. Hypermethylation of MAT1A promoter could participate in its reduced expression in cirrhosis. These observations help to explain the hypermethioninemia, hyperhomocysteinemia and reduced hepatic glutathione content observed in cirrhosis.

Key words: Cirrhosis; DNA methylation; Hepatocarcinoma; Liver; Methionine.

co-ordinated by AdoMet which inhibits the synthesis of methionine from homocysteine and activates cystathionine $\beta$-synthase ( $C B S$ ), the first step of the transsulfuration pathway $(1,2)$. Moreover, AdoMet activates glycine N-methyltransferase (GNMT), an enzyme which accounts for about $1 \%$ of the hepatic cytosol (3), and whose main function is to remove excess AdoMet $(1,2)$. The expression of $G N M T$, betaine homocysteine methyltransferase $(B H M T)$ and $C B S$ is confined mainly to the liver, whereas the expression of methionine synthase $(M S)$ occurs in all tissues $(1,2)$. There are two genes coding for methionine adenosyltransferase (MAT), the enzyme that converts methionine into AdoMet, one $(M A T 1 A)$ expressed exclusively in the liver and a second gene $(M A T 2 A)$ expressed in all tissues and fetal liver (4). As a consequence of this liver-speci- 
fic expression of genes involved in methionine metabolism, and although all tissues can synthesize and utilize AdoMet, the liver is the main place for the metabolism of this amino acid. In humans, up to $85 \%$ of all methylation reactions and as much as $48 \%$ of methionine metabolism occur in the liver (5).

Human liver cirrhosis has been known to be associated with alterations of methionine metabolism for at least 50 years (6). Many patients with alcoholic liver cirrhosis have increased serum methionine $(6-8)$ and homocysteine (9), abnormal clearance of methionine after an oral load of this amino acid $(7,8)$, and diminished hepatic GSH content (10) and MAT activity $(11,12)$. Methionine metabolism has also been investigated in various experimental models of liver disease. Ethanol and $\mathrm{CCl}_{4}$-induced liver injury are associated with a reduction in hepatic AdoMet and an increase in AdoHcy, overall hepatic DNA hypomethylation, reduced hepatic GSH content, and increased serum homocysteine (13-18). The importance of this alteration in the metaholism of methionine for the progression of the disease has been substantiated by the numerous publications showing in experimental models that AdoMet administration reduces liver damage induced by a variety of agents (15-23), and by the recent finding demonstrating that AdoMet treatment

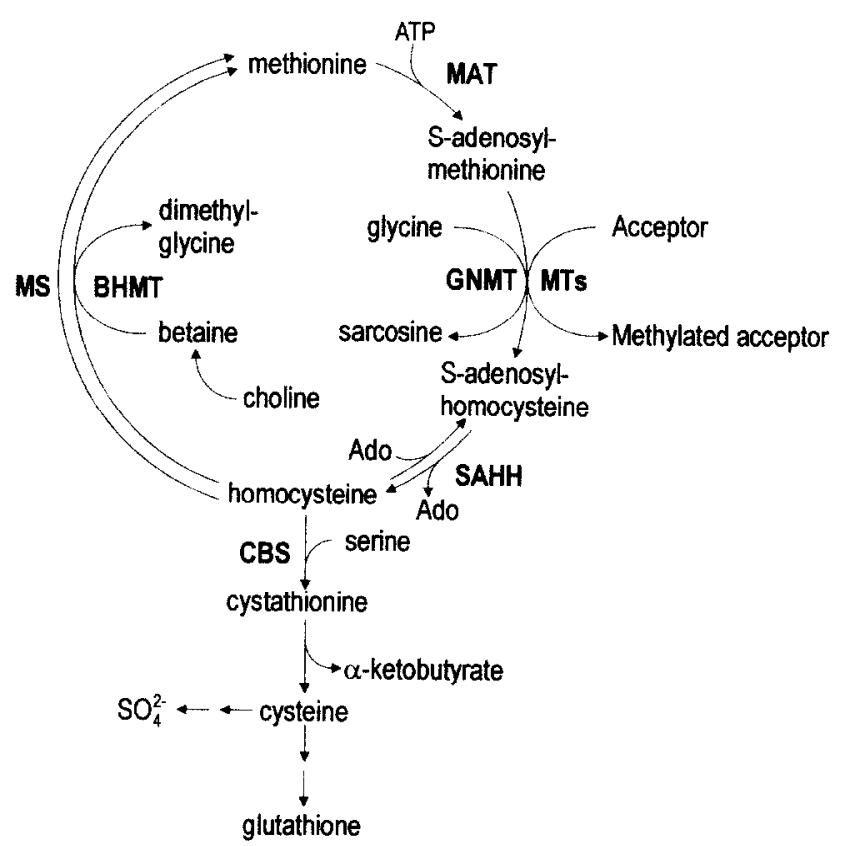

Fig. 1. Liver methionine cycle and transsulfuration pathway. MAT: methionine adenosyltransferase, GNMT: glycine-N-methyltransferase, MTs: methyl transferases, SAHH: S-adenosyl-L-homocysteine hydrolase, CBS: cystathionine $\beta$-synthase, BHMT: betaine-homocysteinemethyltransferase, MS: methionine synthase. improves survival in patients with alcoholic liver cirrhosis (24). However, knowledge of the molecular basis of this alteration of methionine metabolism in human liver cirrhosis and of the mechanism of action of AdoMet is limited. Thus we have examined the mRNA level of MATIA, GNMT, MS, BHMT and CBS in 26 cirrhotic livers, five hepatocellular carcinoma (HCC) tissues and ten control liver tissues.

\section{Materials and Methods}

\section{Pationts}

We have studied a group of 26 patients ( 17 males and 9 females, mean age $54 \pm 8.5$ years) with liver cirrhosis of different etiology $(13 \mathrm{HCV}$ cirrhosis, 10 alcoholic cirrhosis, one HBV cirrhosis, one cryptogenetic cirrhosis and one primary biliary cirrhosis, PBC). The control group for the cirrhotic patients consisted of 10 subjects in whom a cholecystectomy was performed for the treatment of a symptomatic cholelithiasis and who consented to be submitted to a liver biopsy during the surgical procedure. Liver samples were immediately frozen and kept at $-80^{\circ} \mathrm{C}$ until processed. In the subjects from the control group, both the liver function tests and the liver biopsy were normal. This study was approved by the human research review committee of the University of Navarra, Hospital Clinic and Hospital Príncipe de Asturias. Cancerous liver tissues were obtained from five liver patients undergoing surgical resection for primary $\mathrm{HCC}$ (25). The contamination of HCC samples with noncancerous tissue was less than $5 \%$ as determined by histopathology: The control group for the $\mathrm{HCC}$ patients consisted of normal liver tissue obtained from normal liver included in the resected liver specimens of six patients with metastatic colon or breast carcinoma. We were blinded to the clinical characteristics (whether there was hepatitis B or $C_{\text {. etc.). This was mandated }}$ by the Institutional Review Board of the University of Southern California School of Medicine, from where these liver specimens were obtained. These tissues were immediately frozen in liquid nitrogen for subsequent isolation of RNA. Written informed consent was obtained from each patient. The study was approved by University of Southern California School of Medicine's human research review committee.

\section{$R T$ - $P C R$ studies}

Total RNA was extracted from liver biopsies as previously described (25). Aliquots of $2 \mu \mathrm{g}$ were reverse transcribed using M-MLV Reverse Transcriptase (Gibco Life Technologies, MD, USA) and subsequently amplified by polymerase chain reaction (PCR) using the BioTaq DNA Polymerase (Bioline. UK). The primers used for the different genes studied were: 5'-ATG TCA CCC GCG CTC CAA GAC-3' and 5'TCC AGA AGT CCT T"TG GCC TGC $-3^{\prime}$ for MS, 5'-GTC ATG CAG ACC TTC ACC TTC TA-3' and 5'-CTC CTT CAT GAG CTT CAC TG-3' for BHMT, 5'-ACA TGA CCA AGT TCC TGA GC-3' and 5'-GCC ACG AAG TTC AGC AAG TC-3' for CBS, 5'-AAG AGG GCT TCA GTG TGA CG-3' and $5^{\prime}$-AGG CTT GAA GTC GCC CAG GA-3' for GNMT, 5'-TCT CCT CCA GCG TGA TG-3' and $5^{\prime}$-GTT CAC ATC GGA GTC TG for MATIA and $5^{\prime}-\mathrm{ATG}$ AAG TGG GTA ACC-3' and 5'-TAT CAG CAG CTT GGC-3' for IISA. To avoid amplification of genomic DNA which could contaminate our RNA preparations, these primers were designed flanking intronic sequences. $18 \mathrm{~S} \mathrm{rRNA}$ was simultaneously amplified using the Alternate 18S Internal Standards primers set (Ambion. TX. USA) and served as an internal loading control. Reactions were resolved in a $2 \%$ agarose gel, stained with ethidium bromide and quantitated using the Molecular Analyst software (Bio-Rad, Hercules, CA. USA). The 100-bp DNA Ladder molecular weight standards from Gibco Life Technologies were used

DNA extraction and Southern blot analysis Genomic DNA was prepared from control and cirrhotic liver samples as described previously (26). Aliquots of high molecular weight DNA 
$(10 \mu \mathrm{g})$ were digested to completion with $\mathrm{DraI}$ and then either $M s p \mathrm{I}$ or HpaII restriction enzymes (Boehringer Mannheim, Mannheim, Germany). After digestion, samples were loaded on agarose gels, electrophoresed and blotted onto NYTRAN membranes (Schleicher \& Schuell, Keene NH, USA). Hybridizations were carried out with a $0.89 \mathrm{~kb}$ probe derived from the human MATIA promoter (DraI-DraI fragment encompassing from nucleotide -589 to -1479 ) (27) labeled with $\left[\alpha-{ }^{32} \mathrm{P}\right] \mathrm{dCTP}(3000 \mathrm{Ci} / \mathrm{mmol}$, Amersham, Little Chalfont, UK) by random priming using the Megaprime DNA labeling system (Amersham) as reported (26). Membranes were then exposed to Xray films.

RNA extraction and Northern blot analysis

Total RNA was extracted from control livers and HCC samples by the guanidinium thiocyanate method as previously described (25). Aliquots $(20 \mu \mathrm{g})$ of total RNA were electrophoresed, blotted, prehybridized and hybridized as described (25). The probes (25) were labeled with $\left[\alpha-{ }^{32} \mathrm{P}\right] \mathrm{dCTP}(3000 \mathrm{Ci} / \mathrm{mmol}$, Amersham, Little Chalfont, UK) by random priming using the Megaprime DNA labeling system ( $\Lambda$ mersham). Equal loading of the gels was assessed by hybridization with an $18 \mathrm{~S}$ ribosomal RNA probe. Quantitation was performed by scanning densitometry of the $\mathrm{x}$-ray films.

Serum methionine and total homocysteine ( $t H c y)$ determination Serum methionine was determined as described (17). Total serum homocysteine (tHcy) was measured as reported (28), with the modifications described in Deulofeu et al. (29).

Statistics

All data are means \pm SEM. The Mann-Whitney unpaired test was used to compare groups.

\section{Results}

Reduced $m R N A$ levels of the main enzymes involved in methionine metabolism in cirrhotic livers

We assessed MAT1A mRNA levels by RT-PCR in 26 cirrhotic and ten normal livers (Fig. 2). Only three cirrhotic livers ( $11 \%$ ) showed $M A T 1 A$ mRNA abundance comparable to that measured in normal livers. Decreased $M A T 1 A$ mRNA content in liver was observed in 15 cirrhotic livers $(58 \%)$. In eight cirrhotic patients (31\%) hepatic MATIA mRNA level was very low or non-detectable. $M A T 2 A$ expression was not induced in any of the cirrhotic patients (not shown). We also assessed GNMT, MS, BHMT and CBS mRNA content in the same cirrhotic and normal livers by RT-PCR (Fig. 2). GNMT, MS, BHMT and CBS mRNA was very low or undetectable in the majority of the cirrhotic samples $(54 \%, 65 \%, 69 \%$ and $58 \%$, respectively). The percent of cirrhotic livers showing reduced mRNA abundance for GNMT, MS, BHMT and $C B S$ was $42 \%$, $35 \%, 19 \%$ and $15 \%$, respectively. In the case of $G N M T$, $B H M T$ and $C B S$, one, three and seven patients, respectively, showed mRNA levels similar to those determined in normal livers. None of the cirrhotic livers
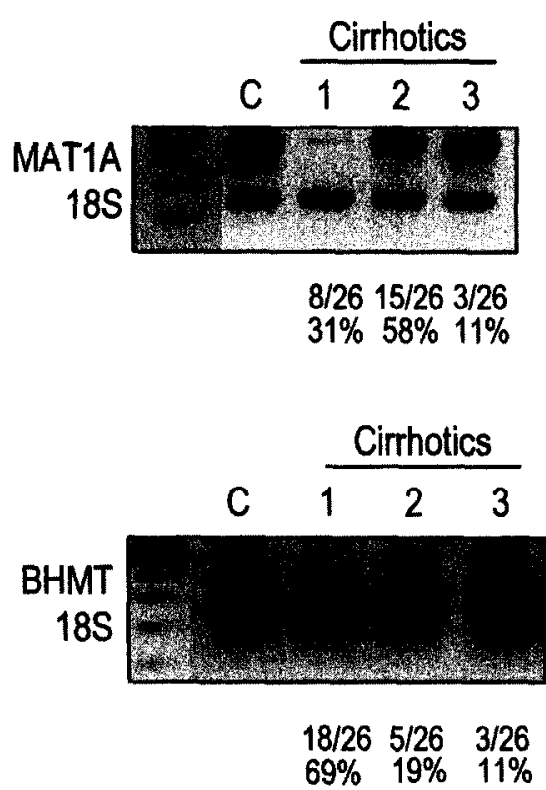
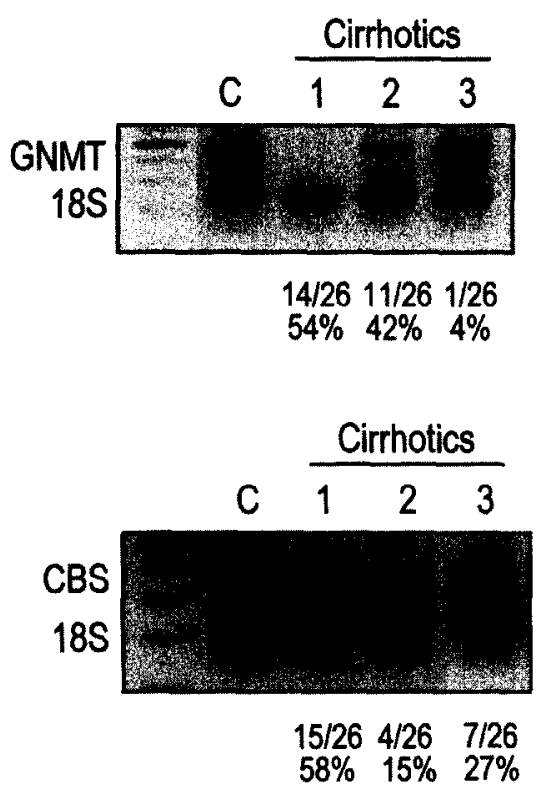
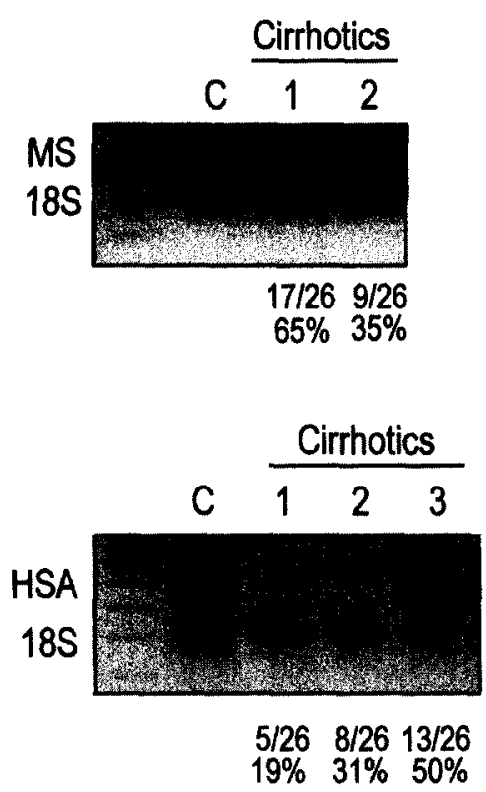

Fig. 2. Expression of methionine metabolism genes in the liver of cirrhotic and control patients. $\mathbf{C}$ : normal livers (controls). Cirrhotics were divided into three groups according to the levels of expression of the different genes tested: group 1: patients with very low or non-detectable expression, group 2: patients with a level of expression lower than controls, group 3: patients with a level of expression similar to controls. The number of patients per group is indicated for each gene analyzed. Serum albumin (HSA) expression in control and cirrhotic patients is also shown. Representative RT-PCR reactions are shown for the 26 patients and 10 normal livers. 18S ribosomal RNA was used as internal control. The left lane of each gel shows the molecular weight markers, the most intense band corresponds to $600 \mathrm{bp}$. 
showed MS mRNA levels comparable to those measured in normal livers. Human serum albumin ( $H S A)$ mRNA level was normal in $50 \%$ of the cirrhotic livers, reduced in $31 \%$ of the tissues, and very low or nondetectable in $19 \%$ of the samples (Fig. 2). Patients with a marked reduction in the expression of a given gene (group one) tended to be in this same group for all genes tested. For instance, out of the 14 patients in group one for GNMT (Fig. 2), the same 14 patients were in group one for $B H M T, 12$ in group 1 for $C B S$ and 11 in group 1 for $M S$. The percent of livers with very low or non-detectable levels of mRNA for the various genes of methionine metabolism analyzed was higher for tissues from patients with $\mathrm{HCV}$ cirrhosis than with alcoholic cirrhosis (Fig. 3).

In order to evaluate if the reduced expression of the various genes involved in methionine metabolism was related to the severity of the disease, expressed as the Child-Pugh score (30), patients were divided into two groups. One group (group 1) included patients showing normal or only reduced levels of mRNA for at least three of the five genes analyzed involved in methionine metabolism. The second group (group 2) included those patients with very low or undetectable levels of
mRNA for all or four of the five genes analyzed involved in methionine metabolism. The mean value for the Child-Pugh score was significantly higher in the cirrhotic patients in group $2(9.0 \pm 0.7)$ than in the cirrhotic patients in group $1(7.1 £ 0.4, p<0.03)$.

The mean value for tHcy was significantly higher in the cirrhotic patients in group $2(17.0 \pm 2.0 \mu \mathrm{M})$ than in group $1(12.0 \pm 1.6 \mu \mathrm{M}, p<0.05)$. In agreement with previous results (9), the tHcy concentration in our group of cirrhotics $(14.1 \pm 1.3 \mu \mathrm{M})$ was significantly higher than in the control group $(8.1 \pm 0.9 \mu \mathrm{M}$, $p<0.03)$. In agreement with previous publications $(6-$ $8)$, fasting serum methionine in cirrhotics $(106.3 \pm 34.7$ $\mu \mathrm{M})$ was higher than in the control group (30.8 \pm 4.8 $\mu \mathrm{M}, p<0.01)$. Differences in methionine concentration in cirrhotic patients in groups $1(46.2 \pm 8.6 \mu \mathrm{M})$ and 2 $(171.8 \pm 68.1 \mu \mathrm{M}, p<0.01)$ were also statistically significant.

Reduced $m R N A$ levels of the main enzymes involved in methionine metabolism in HCC tissues

We have reported a switch in gene expression from $M A T I A$ to $M A T 2 A$ in various human-derived cancer cell lines and HCC tissues resected from patients (25).
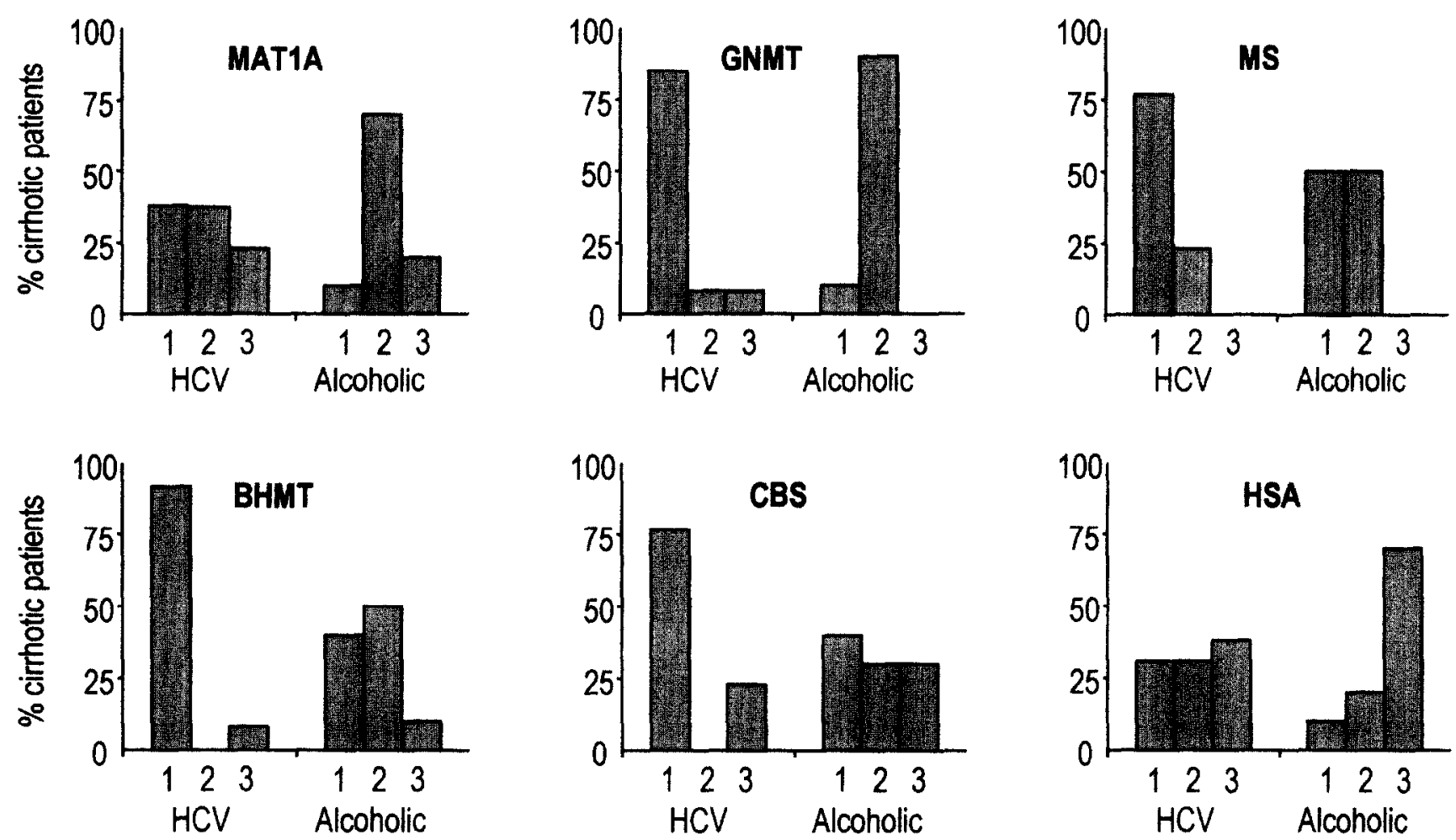

Fig. 3. Expression of liver methionine metabolizing genes and serum albumin (HSA) in cirrhotic patients according to the etiology of the disease: HCV cirrhosis or alcoholic cirrhosis. Patient groups are as defined in the legend to Fig. 2, the percentage of patients in each group is shown. 
As expected, in the five $\mathrm{HCC}$ tissues used in the present experiments the mRNA content of $M A T 2 A$ increased about 6-fold in respect to the average control liver (Fig. 4A) and in HCC tissues MATIA mRNA content was very low or non-detectable (not shown). We next examined the mRNA abundance by RT-PCR of the main enzymes of methionine metabolism in these $\mathrm{HCC}$ tissues. BHMT, CBS, GNMT and $M S$ mRNA content was markedly decreased in HCC tissues compared with normal liver (Fig. 4B). The average mRNA abundance of $B H M T, C B S, G N M T$ and $M S$ in HCC tissues was $48 \%, 25 \%, 34 \%$ and $35 \%$, respectively, of that determined in normal liver.

\section{Hypermethylation of hepatic MAT1A promoter in} human cirrhosis

We have recently reported evidence showing that $M A T I A$ silencing during liver transformation is me-

A

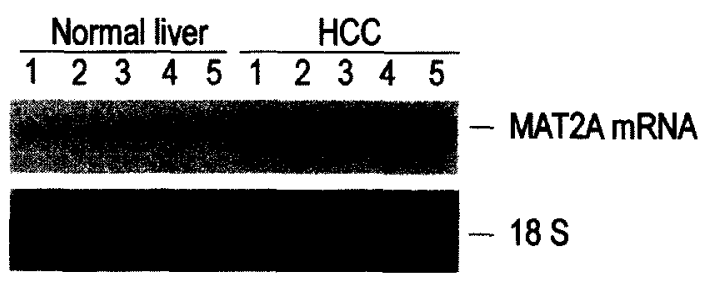

B

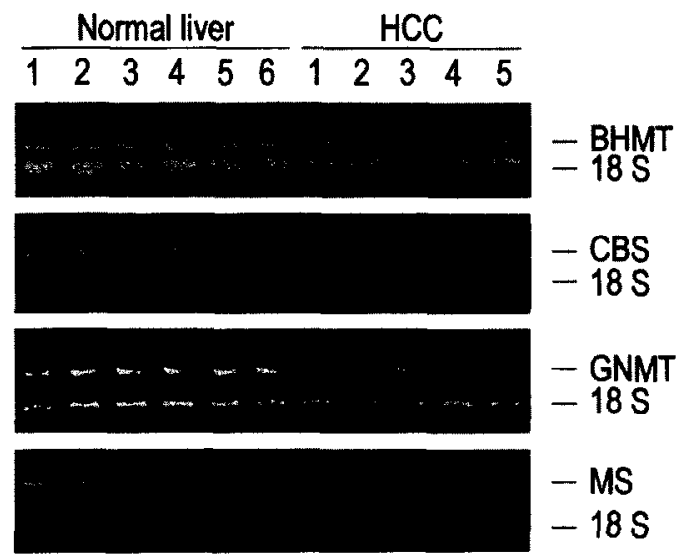

Fig. 4. A. Expression of MAT2A in human hepatocarcinoma tissues and normal liver tissues as analyzed by Northern blotting. Hybridization with a $18 \mathrm{~S} r R N A$ probe was carried out as loading control. B. Expression of BHMT, CBS, GNMT and MS in human hepatocarcinoma tissues and normal liver tissues as analyzed by quantitative $R T-P C R$. $18 S$ ribosomal RNA was used as internal control. Samples and controls are as described in Materials and Methods. diated by methylation of the gene promoter and histone deacetylation (26). Additionally, we have observed that $M A T 1 A$ promoter is hypermethylated in livers from $\mathrm{CCl}_{4}$-induced cirrhotic rats (26). MATIA promoter methylation was assessed in ten cirrhotics (five with $\mathrm{HCV}$ cirrhosis and five with alcoholic cirrhosis) and five normal livers by methylation-sensitive restriction enzyme analysis as described in Materials and Methods. Fig. 5 shows a representative experiment with the results of MAT1A promoter methylation obtained in two normal livers, two alcoholic and two HCV cirrhotic livers. The probe used in this study corresponds to a $0.89 \mathrm{~kb}$ DraI-DraI fragment (nucleotides -589 to -1479 ) of the human MATIA promoter (27), which contains a single $M s p \mathrm{I} / \mathrm{HpaII}$ restriction site (located at position -737). As can be observed in Fig. 5, digestion of control liver samples with $\operatorname{DraI}$ and either $M s p \mathrm{I}$ or $\mathrm{HpaII}$ yields one fragment of $0.74 \mathrm{~kb}$ which is recognized by this probe. In cirrhotic liver samples, after DraI treatment, $M s p I$ digestion generated the same $0.74 \mathrm{~kb}$ band present in control samples. However, HpaII treatment yielded a 0.89 $\mathrm{kb}$ band, indicating that this enzyme did not cut and thus that MATIA promoter is hypermethylated at this site. MATIA promoter methylation was increased in the liver from all cirrhotic patients assessed independently of the etiology of the disease.

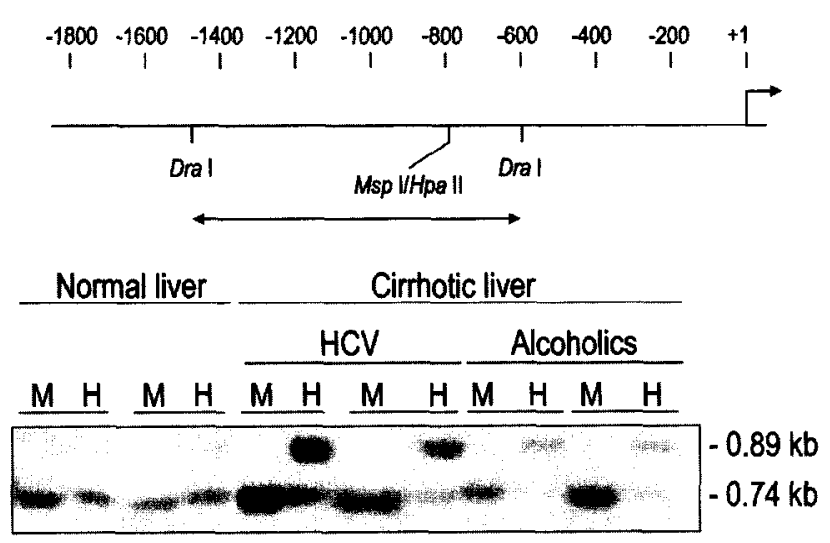

Fig. 5. Methylation status of MAT1A $5^{\prime}$ region in normal liver and cirrhotic liver tissue. Restriction map of MAT1A promoter indicating the location of the $\mathrm{Msp} / / \mathrm{HpaII}$ restriction site and the $0.88 \mathrm{~kb}$ Dral-DraI probe used in this analysis. Lower panel shows a representative Southern blot analysis of genomic DNA from normal, $\mathrm{HCV}$ and alcoholic cirrhotic liver after digestion with $\mathrm{DraI}$ and $\mathrm{MspI}(M)$ or $\mathrm{HpaII}(H)$ performed with the probe described above. The molecular size of the bands detected with this probe is indicated. 


\section{Discussion}

Our results show that the alterations of methionine metabolism in human liver cirrhosis can be ascribed to a marked reduction in the abundance of the mRNA of the main enzymes involved in the metabolism of this amino acid. Although not measured in the present work, the corresponding enzyme protein levels are likely to be reduced in a chronic situation such as liver cirrhosis. The reduction in $M A T I A$ mRNA content can explain the previously described increase in serum methionine $(6,7)$ and abnormal clearance of methionine after an oral load of this amino acid (7) observed in patients with liver cirrhosis of different origins. In agreement with previous results (9), we observed an increase in tHcy in cirrhosis, which could be explained by the deficiencies in both cystathionine synthesis and homocysteine remethylation in the liver of these patients caused by the reduced abundance of $C B S, M S$ and $B H M T$ mRNA. In the liver, homocysteine may potentiate the fibrogenic effect of other agents such as ethanol and cytokines. Thus, we have recently shown that homocysteine is able to induce the expression of tissuc inhibitor metalloprotcinase-1 (TIMP-1) and $\alpha 1$ (I) procollagen in rat hepatic stellate cells (31). The reduced content of $C B S$ mRNA and the consequent deficiency of cystathionine synthesis could also explain the reduced content of hepatic GSH (10), plasma taurine (8) and urinary sulfate (7) in human liver cirrhosis. It has been previously demonstrated that in cirrhotic patients methionine clearance (8) and tHcy levels in plasma (9) correlate with the degree of liver dysfunction as determined by the Child-Pugh score. Accordingly, this work shows that in those patients with more severe disease, expressed as the Child-Pugh score, the expression of the main genes involved in methionine metabolism was more compromised.

Impairment of the metabolism of methionine in rats by feeding a diet deficient in choline, $\mathbf{B}_{12}$, folate and methionine leads to an enhancement of chemically-induced hepatocarcinogenesis (32) and to the spontaneous appearance of these cancers $(33,34)$. These facts support the existence of a strong link between a defective one-carbon metabolism in liver and the development of neoplasia. A significant number of cirrhotic patients, especially those with HCV infection, develop HCC. In this regard the cirrhotic liver can be considered as a precancerous condition $(35,36)$. The present observation showing that the mRNA content of $M S$ and $B H M T$ is reduced or non-detectable in a large majority of cirrhotic patients (only three cirrhotics had normal levels of BHMT $\mathrm{mRNA}$ and none of them had normal levels of $M S \mathrm{mRNA}$ ), suggests that this defect in the remethylation of homocysteine may contribute to the development of $\mathrm{HCC}$ in cirrhosis.

In $\mathrm{HCC}$ tissues the mRNA content of GNMT, $B H M T, M S$ and $C B S$ was markedly diminished with respect to normal liver and, and as previously described (25), a switch in gene expression from $M A T I A$ to $M A T 2 A$ was observed. This indicates that the methionine cycle and the transsulfuration pathway are both operating in $\mathrm{HCC}$ tissues; however, the capacity of these two pathways is markedly diminished as compared to that of a normal liver. First, while the products of MATIA are two MAT isoenzymes with high capacity to remove methionine from serum, the product of MAT2A is an enzyme with high affinity but low capacity to metabolize this amino acid $(1,4)$. Second, the reduced abundance of the mRNA of $C B S, B H M T$ and $M S(25 \%, 48 \%$ and $35 \%$, respectively, of that in normal liver) indicate a reduced capacity of the $\mathrm{HCC}$ tissue to catabolize homocysteine coming to the liver from other tissues and an impaired transsulfuration pathway as compared to that of normal liver. This reduced capacity to remethylate homocysteine, due to impaired expression of $M S$ and $B H M T$, may explain the relative methionine dependence reported for transformed hepatic cells (37). In addition, the concomitant reduction in CBS expression, leading to elevated homocysteine levels, contributes to explain the increased production of homocysteine thiolactone, a highly reactive form of homocysteine (38), by transformed cells (39). Despite these deficiencies, the activity of the methionine cycle in $\mathrm{HCC}$ is probably sufficient to sustain the tumor necessities of AdoMet, methionine (through remethylation of homocysteine), folate cycling, choline metabolism and GSH content. Additionally, these changes in the pattern of expression of methionine metabolizing enzymes reflect the dedifferentiation of the hepatocarcimoma cell, and thus may be of diagnostic or prognostic value.

The finding that MATIA promoter is hypermethylated in human liver cirrhosis, in an environment of global DNA hypomethylation (37), and our previous observations $(26,40)$ showing that silencing of $M A T 1 A$ is mediated by methylation of the gene and histone deacetylation, suggest that the reduced abundance of the mRNA of the enzymes involved in methionine metabolism in cirrhosis is the result of an active process and not only the consequence of an overall reduction of hepatic gene transcription. MATIA promoter was hypermethylated in the cirrhotic patients independently of the etiology of the disease, and as we reported previously in a rat model of $\mathrm{CCl}_{4}$-induced cirrhosis (26), these observations indicate that this process can 
be triggered under liver-damaging conditions, independently of the noxious agent.

\section{Acknowledgements}

This work was supported by grants from the Plan Nacional de I+D (SAF 96/0108, SAF 98/0132), Europharma and Knoll to J.M.M. NIH grant DK51719 to S.C.L. FIS grant $98 / 1082$ to JC. Gobierno de Navarra grant $923 / 98$ to MAA. Grant \#ROI AA12677 from the National Institute on Alcohol $\Lambda$ buse and Alcoholism, USA, to S. C. Lu, J. M. Mato and M. A. Avila. We thank Dr. Javier Díez for his help with homocysteine determinations. Technical support from E. Fernández is acknowledged.

\section{References}

1. Mato JM, Alvarez L, Ortiz P, Pajares MA. S-Adenosylmethionine synthesis: molecular mechanisms and clinical implications. Pharmacol Ther 1997; 73: 265-80.

2. Finkelstein JD. Methionine metabolism in mammals. J Nutr Biochem 1990; 1: 228-36.

3. Cook RJ, Wagner C. Glycine N-methyltransferase is a folate binding protein. Proc Natl Acad Sci USA 1984; 81: 3631-4.

4. Kotb M, Mudd SH, Mato JM, Geller AM, Kredich NM, Chou JY, et al. Consensus nomenclature for the mammalian methionine adenosyltransferase genes and gene products. Trends Genet (England) 1997; 13: 51-2.

5. Mudd SH, Poole JR. Labile methyl balances for normal humans on various dietary regimens. Metabolism 1975; 24: 721-35.

6. Kinsell LW, Harper HA, Marton HC, Michael GD, Weiss HA. Rate of disappearance from plasma of intravenously administered methionine in patients with liver damage. Science 1947; 106: $589-90$.

7. Horowitz JH, Rypins EB, Henderson JM, Heymsfield SB, Moffit SD, Bain R, et al. Evidence for impairment of transsulfuration pathway in cirrhosis. Gastroenterology 1981; 81: 668-75.

8. Marchesini G, Bugianesi E, Bianchi G, Fabbri A, Marchi E, Zoli $M$, et al. Defective methionine metabolism in cirrhosis: relation to severity of liver disease. Hepatology 1992; 16: 149-55.

9. Lambert D, Benhayoun S, Adjalla C, Gelot MM, Renkes P, Gerard $\mathrm{P}$, et al. Alcoholic cirrhosis and cobalamin metabolism. Digestion 1997; 58: 64-71.

10. Vendemiale G, Altomare E, Trizio T, Le Gracie C, Di Padova C, Salerno MT, et al. Effect of oral S-adenosyl-L-methionine on hepatic glutathione in patients with liver disease. Scand J Gastroenterol 1989; 24: 407-15.

11. Martín-Duce A, Ortiz P, Cabrero C, Mato JM. S-Adenosyl-Lmethionine synthetase and phospholipid methyltransferase are inhibited in human cirrhosis. Hepatology 1988; 8: 65-8.

12. Cabrero C, Martin-Duce A, Ortiz P, Alemany S, Mato JM. Specific loss of the high-molecular weight form of S-adenosyl-L-methionine synthetase in human liver cirrhosis. Hepatology 1988; 8: $1530-4$.

13. Barak AJ, Beckenhauer HC, Tuma DJ, Badakash S. Effects of prolonged ethanol feeding on methionine metabolism in rat liver. Biochem Cell Biol 1987; 63: 230-3.

14. Trimble K, Molloy AM, Scott J, Weir DG. The effect of ethanol on one-carbon metabolism: increased methionine catabolism and lipotrope methyl-group wastage. Hepatology 1993; 18: 984-9.

15. Lieber CS, Casini A, DeCarli LM, Kim C, Lowe N, Sasaki R, et al. S-Adenosyl-L-methionine attenuates alcohol-induced liver injury in the baboon. Hepatology 1990; 11: 165-72.

16. Corrales F, Gimenez A, Alvarez L, Caballeria J, Pajares MA, Andreu $\mathrm{H}$, et al. S-Adenosylmethionine treatment prevents $\mathrm{CCl}_{4^{-}}$ induced S-adenosylmethionine synthetase inactivation and attenuates liver injury. Hepatology 1992; 16: 1022-7.

17. Varela-Moreiras G, Alonso-Aperte E, Rubio M, Gassó M, Deulofeu R, Alvarez L, et al. Carbon tetrachloride-induced hepatic injury is associated with global DNA hypomethylation and homocysteinemia: effect of S-adenosylmethionine treatment. Hepatology 1995; 22: 1310-5.

18. García-Ruiz C, Morales A, Culell A, Ballesta A, Rodes J, Kaplowitz $\mathrm{N}$, et al. Feeding S-adenosyl-L-methionine attenuates both ethanol-induced depletion of mitochondrial glutathione and mitochondrial dysfunction in periportal and perivenous rat hepatocytes. Hepatology 1995; 21: 207-14.

19. Bray GP, Tredger M, Williams R. S-Adenosylmethionine protects against acetaminophen hepatotoxicity in two mouse models. Hepatology 1992; 15: 297-301.

20. Stramentinoli G, Gulano M, Ideo G. Protective role of S-adenosyl-L-methionine on liver damage induced by $D$-galactosamine in rats. Biochem Pharmacol 1978; 27: 1431-3.

21. Pascale RM, Marras V, Simile MM, Daino L, Pinna G, Bennati $\mathrm{S}$, et al. Chemoprevention of rat liver carcinogenesis by $\mathrm{S}$-adenosyl-L-methionine: a long-term study, Cancer Res 1992; 52: 4979_ 86.

22. Pascale RM, Simile MM, Feo F. Genomic abnormalities in hepatocarcinogenesis. Implications for a chemopreventive strategy. Anticancer Res 1993; 13: 1341-56.

23. Chawla RK, Bonkoovsky HL, Galambos JT. Biochemistry and pharmacology of S-adenosyl-L-methionine and rationale for its use in liver disease. Drugs 1990; 40 (Suppl. 3): 98-110.

24. Mato JM, Cámara J, Fernández de Paz J, Caballería L, Coll $S$, Caballero $A$, et al. S-Adenosylmethionine in alcoholic liver cirrhosis: a randomized, placebo-controled, double-blind, multicenter clinical trial. J Hepatol 1999; 30: 1081-9.

25. Cai J, Sun W-M, Hwang J-J, Stain SC, Lu SC. Changes in Sadenosylmethionine synthetase in human liver cancer: molecular characterization and significance. Hepatology 1996; 24: 1090-7.

26. Torres L, Avila MA, Carretero MV, Latasa MU, Caballería J, López-Rodas G, et al. Liver-specific methionine adcnosyltransferase $M A T I A$ gene expresión is associated with a specific pattern of promoter methylation and histone acetylation. Implications for MAT'IA silencing during transtormation. FASEB $\mathrm{J}$ 2000; 14: 95-102.

27. Zeng $Z$, Huang Z-Z, Chen C, Yang $H$, Mao Z, Lu SC. Cloning and functional characterization of the 5 '-flanking region of human methionine adenosyltransferase 1 A gene. Biochem J 2000; 346: 475-82.

28. Ueland P, Refsum H, Stabler S, Malinow R, Andersson A, Allen RH. Total homocysteine in plasma or serum: methods and clinical application. Clin Chem 1993; 39: 1764-79.

29. Deulofeu R, Giralt M, Aibar C, Bauchet C, Varela-Moreiras G, Casals $F$, et al. Determinación de homocisteina en plasma por cromatografía líquida de alta resolución. Aplicación al estudio de enfermos afectos de enfermedad vascular cerebral y periférica. Química Clínica 1996; 15: 77-84.

30. Pugh RNH, Murray-Lyon IM, Dawson JL, Pietroni MC, Williams R. Transection of the oesophagus for bleeding oesophageal varices. Br J Surg 1973; 60: 646-9.

31. Torres L, García-Trevijano ER, Rodríguez JA, Carretero MV, Bustos M, Fernández E, et al. Induction of TIMP-1 expression in rat hepatic stellate cells and hepatocytes: a new role for homocysteine in liver fibrosis. Biochim Biophys Acta 1999; 1455: 1222.

32. Wainfan E, Dizic M, Stender M, Christman J. Rapid appearance of hypomethylated DNA in livers of rats fed cancer-promoting, methyl-deficient diets. Cancer Res 1989; 49: 4094-7.

33. Newberne PM, Rogers AE. Labile methyl groups and the promotion of cancer. Annu Rev Nutr 1986; 6: 407-32.

34. Saito R, Jahnke-Spinnenweber J, Shinozuka H, Lombardi B. On the role of compensatory mitogenesis in the hepatocarcinogenicity of choline and multiple-lipotrope devoid diets. Carcinogenesis 1994; 15: 1413-9. 
35. Tsuda $H$, Hirohashi S, Shimosato $Y$, Terada M, Hasegawa $H$. Clonal origin of atypical adenomatous hyperplasia of the liver and clonal identity with hepatocellular carcinoma. Gastroenterology 1988; 95: $1664-6$.

36. Yasiu H, Hino O, Ohtake K, Machinami R, Kitagawa T. Clonal growth of hepatitis B virus-integraled hepalucyles in cirrhotic liver nodule. Cancer Res 1992; 52: 6810-4.

37. Hoffman RM. Altered methionine metabolism, DNA methylation and oncogene expression in carcinogenesis. Biochim Biophys Acta $1984 ; 738: 49 \sim 87$.
38. Jakubowski H. Protein homocysteinylation: possible mechanism underlying pathological consequences of elevated homocysteine levels. FASEB J 1999; 13: 2277-83.

39. Jakubowski H, Goldman E. Synthesis of homocysteine thiolactone by methyonil-tRNA synthetase in cultured mammalian cells. FEBS Lell 1993, 317: 237-40.

40. Torres L, López-Rodas G, Latasa MU, Carretero MV, Boukaba A, Rodríguez JL. et al. DNA methylation and histone acetylation of rat methionine adenosyltransferase $1 \mathrm{~A}$ and $2 \mathrm{~A}$ genes is tissuespecific. Int J Biochem Cell Biol 2000; 32: 397-404. 